\title{
The impact of disease severity on paradoxical association between body mass index and mortality in patients with acute kidney injury undergoing continuous renal replacement therapy
}

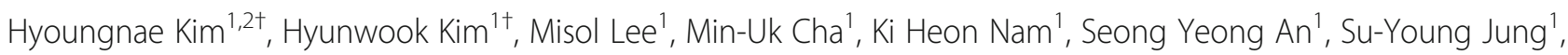
Jong Hyun Jhee', Seohyun Park', Hae-Ryong Yun', Youn Kyung Kee', Hyung Jung Oh', Jung Tak Park', Tae Ik Chang ${ }^{4}$, Tae-Hyun Yoo', Shin-Wook Kang ${ }^{1}$ and Seung Hyeok Han ${ }^{1 *}$ (D)

\begin{abstract}
Background: Association between high body mass index (BMI) and survival benefit is confounded by comorbid conditions such as nutritional status and inflammation. Patients with acute kidney injury (AKI), particularly those receiving continuous renal replacement therapy (CRRT), are highly catabolic and more susceptible to loss of energy. Herein, we evaluated whether disease severity can modify the relationship between BMI and mortality.

Methods: We conducted an observational study in 1144 patients who had undergone CRRT owing to various causes of AKI between 2010 and 2014. Patients were categorized into four groups; underweight $\left(<18.5 \mathrm{~kg} / \mathrm{m}^{2}\right)$, normal $\left(18.5-22.99 \mathrm{~kg} / \mathrm{m}^{2}\right)$, overweight $\left(23.0-24.99 \mathrm{~kg} / \mathrm{m}^{2}\right)$, and obesity $\left(\geq 25 \mathrm{~kg} / \mathrm{m}^{2}\right)$ according to BMl classification by the Committee of Clinical Practice Guidelines and Korean Society for the Study of Obesity. More severe disease was defined as sepsis-related organ failure assessment (SOFA) score of $\geq$ a median value of 12 . The study endpoint was death that occurred within 30 days after the initiation of CRRT.

Results: The mean age was 63.2 years and 439 (38.4\%) were females. The median BMl was $23.6(20.9-26.2) \mathrm{kg} / \mathrm{m}^{2}$. The obese group were younger and higher SOFA score than normal BMI group. In a multivariable Cox regression analysis, we found a significant interaction between BMI and SOFA score $(P<0.001)$. Furthermore, obese patients were significantly associated with a lower risk of death as compared to normal BMl group after adjusting confounding factors [hazard ratio (HR), $0.81 ; 95 \%$ confidence interval $(C \mathrm{Cl}), 0.68-0.97 ; P=0.03]$. This association was only evident among patients with high severity (HR, 0.61; $95 \% \mathrm{Cl}, 0.48-0.76, P<0.001)$. In contrast, in those with low severity, survival benefit of high BMl was lost, whereas underweight was associated with an increased risk of death ( $\mathrm{HR}, 1.74 ; 95 \% \mathrm{Cl}, 1.16-2.60 ; P=0.007)$.
\end{abstract}

Conclusion: In this study, we found a survival benefit of high BMI in AKI patients undergoing CRRT, particularly in those with more disease severity; the effect was not observed in those with less disease severity.

Keywords: Acute kidney injury, Body mass index, Continuous renal replacement therapy, Disease severity, Mortality

\footnotetext{
*Correspondence: hansh@yuhs.ac

${ }^{\dagger}$ Equal contributors

${ }^{1}$ Department of Internal Medicine, Institute of Kidney Disease Research,

Yonsei University College of Medicine, 50-1 Yonsei-ro, Seodaemun-Gu, Seoul

03722, South Korea

Full list of author information is available at the end of the article
} 


\section{Background}

Obesity has recently emerged as an important public health problem worldwide. It is indeed associated with hypertension, dyslipidaemia, and diabetes mellitus (DM) and obese individuals who have these comorbid conditions are at a high risk of developing cardiovascular and cerebrovascular diseases [1]. Obesity is also highly associated with the development of chronic kidney disease (CKD), microalbuminuria, and overt proteinuria [2]. Interestingly, obesity is commonly observed in many critically ill patients who are admitted to the intensive care unit (ICU). In a previous meta-analysis from the United States, approximately $30 \%$ of ICU patients had a body mass index (BMI) of $\geq 30 \mathrm{~kg} / \mathrm{m}^{2}$, and duration of mechanical ventilation and length of ICU stay were longer in these patients [3].

Acute kidney injury (AKI) commonly occurs and is a serious problem especially in critically ill patients because complications caused by AKI can lead to adverse outcomes such as increased length of hospital stay, high mortality, and progression to CKD [4]. Because obese patients are burdened with high comorbidities, they are more likely to develop AKI and suffer from more serious complications than non-obese patients. However, there has been conflicting results on the association between AKI, obesity, and mortality. In fact, previous studies have shown that obese patients had high incidence of AKI and more severe kidney injury [5-8], resulting in increased mortality $[6,9,10]$. Nevertheless, there have been several reports that obesity exhibited an inverse or null relationship with mortality [5, 11-15]. In fact, some recent studies clearly showed that critically ill patients with obesity have survival benefit while they are treated in the ICU $[7,16]$.

One possible mechanism of obesity paradox is that high nutritional reserve of obese patients plays an important role during acute life-threatening illness [17]. Interestingly, recent observational studies reported that the relationship between obesity and mortality is confounded by comorbid conditions. In these studies, survival benefit of obese patients was observed only in patients with high Creactive protein (CRP), but not in those with low CRP [18]. In addition, among patients with obesity, malnourished patients had worse outcomes than those in relatively good nutritional status [19]. Of note, patients with AKI are more likely to have high comorbidities and high disease severity. In particular, these patients are highly inflamed and deprived of nutrition because of increased protein catabolism and high energy consumption. This process can be more deteriorated when disease severity is high. Thus, we hypothesized that survival benefit of obesity is more evident under high disease severity condition. In this study, we sought to examine whether disease severity can modify the relationship between obesity and mortality in critically ill patients and conducted an observational study in patients with AKI who underwent continuous renal replacement therapy (CRRT).

\section{Methods}

\section{Patient selection}

This study retrospectively examined the relationship between body mass index and mortality by disease severity. Figure 1 presents a flow chart depicting the selection of subjects. We selected 1144 adult patients who were treated with CRRT in the ICU at two medical centers, Yonsei University Severance Hospital and National Health Insurance Service Medical Center Ilsan hospital between January 2010 and December 2014. Among 2391 patients who were initially assessed for study eligibility, 1247 patients who met following criteria were excluded: 1) $\leq 18$ or $\geq 75$ years old, 2) end-stage renal disease (ESRD) on dialysis, 3) stage 4 malignancy, or 4) no data for BMI. The study was approved by the Institutional Review Board (IRB) of each center. Since current study was a retrospective observational study and the study subjected de-identified, the IRB waived the need for written consent from the patients.

\section{Data collection}

We reviewed electronic medical records and collected demographic and laboratory data. BMI was determined based on the formula of weight $(\mathrm{kg}) /$ height $\left(\mathrm{m}^{2}\right)$. Weight and height of all patients were measured upon ICU admission. To evaluate the severity of the patients' comorbidities,

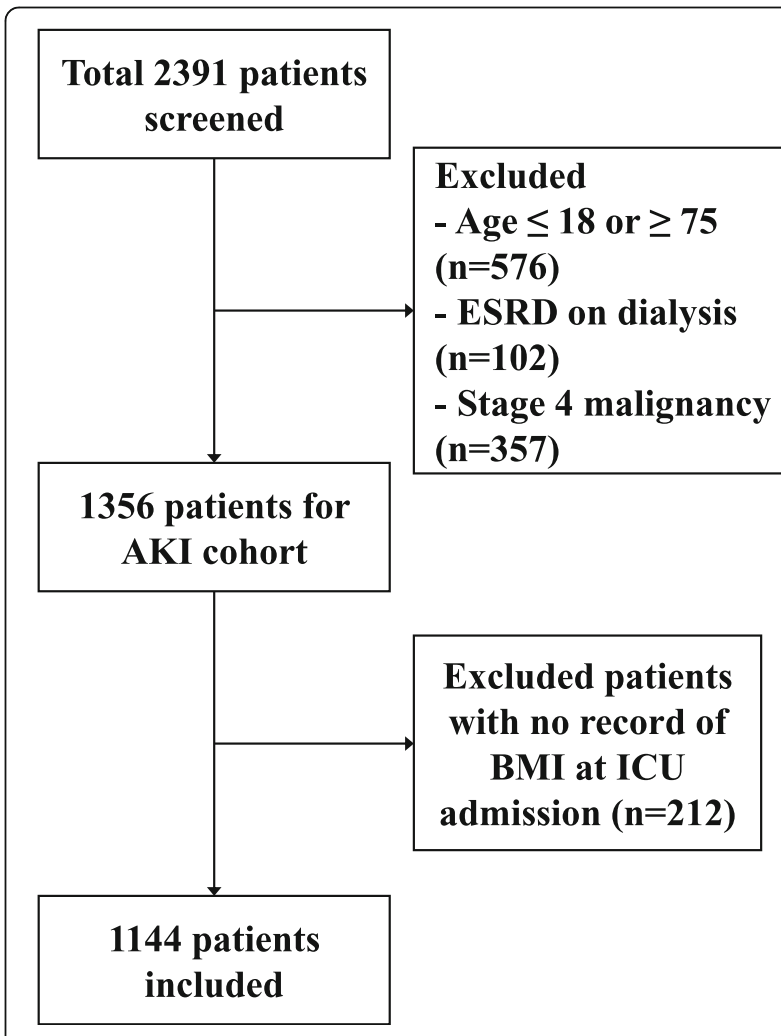

Fig. 1 Flowchart of participants in the cohort. Abbreviations: AKl, acute kidney injury; ESRD, end stage renal disease; BMl, body mass index 
the Charlson comorbidity index (CCI) was calculated by using the score system as previously proposed [20]. Blood tests were done immediately after ICU admission and used for baseline data. The measured laboratory data included white blood cell (WBC) count, haemoglobin, haematocrit, platelet, prothrombin time, partial thromboplastin time, CRP, cholesterol, albumin, blood urea nitrogen, and creatinine. The Modification of Diet in Renal Disease equation [21] was used to determine the baseline estimated glomerular filtration rate (eGFR). The sepsis-related organ failure assessment (SOFA) score and Acute Physiology and Chronic Health Evaluation (APACHE) II score were also calculated based on data for the average vital signs, $\mathrm{PaO} 2$, $\mathrm{FiO} 2$, and Glasgow coma scale score in the first $24 \mathrm{~h}$ of ICU admission.

\section{CRRT protocol}

Upon the development of AKI in ICU patients, nephrologists intervened and decided whether or not to begin CRRT in those who were critically ill. Generally, CRRT was applied in patients with sustained oliguria, uncontrolled volume overload, hyperkalemia or metabolic acidosis. All patients received continuous veno-venous haemodiafiltration by using a Prisma (Gambro Co., Ltd., Hechingen, Germany), Prismaflex (Gambro Co., Ltd), or multiFiltrate (Fresenius Medical Care GmbH, Bad Homburg, Germany) machine, through the internal jugular, subclavian, or femoral vein. CRRT machines were installed, and the system was maintained by trained and educated nurses. Biocompatible polyethersulphone membranes were used in all CRRTs. Pre-filter replacement was loaded with bicarbonate-containing fluid, and a pre-dilution method was applied. CRRT was started at a blood flow rate of $100 \mathrm{~mL} / \mathrm{min}$, and this was increased up to $150 \mathrm{~mL} / \mathrm{min}$. The total effluent volume as a sum of dialysis and replacement dose was targeted to deliver $\geq 35 \mathrm{~mL} \cdot \mathrm{kg}^{-1} \cdot \mathrm{h}^{-1}$ in all patients.

\section{Definition}

According to the World Health Organization (WHO) BMI classification, the criteria for obesity and overweight are $\geq 30 \mathrm{~kg} / \mathrm{m}^{2}$ and $\geq 25 \mathrm{~kg} / \mathrm{m}^{2}$, respectively. However, these cut-off values can be lowered for Asian populations. The prevalence of obesity in Asians by the conventional criteria is much lower and Asians confront higher metabolic risk even under BMI of $30 \mathrm{~kg} / \mathrm{m}^{2}$ compare to other ethnic groups [22]. In fact, Korean individuals with a BMI of 23 to $24.9 \mathrm{~kg} / \mathrm{m}^{2}$ are at higher risk of type 2 diabetes and hypertension as compared to those within the normal BMI range. Therefore in 2014, the Committee of Clinical Practice Guidelines and Korean Society for the Study of Obesity [23] proposed BMI classification as follows; underweight $\left(<18.5 \mathrm{~kg} / \mathrm{m}^{2}\right)$, normal $\left(18.5-22.99 \mathrm{~kg} / \mathrm{m}^{2}\right)$, overweight $\left(23.0-24.99 \mathrm{~kg} / \mathrm{m}^{2}\right)$, and obesity $\left(\geq 25 \mathrm{~kg} / \mathrm{m}^{2}\right)$. In this study, we followed these criteria to define obesity. In addition, disease severity was assessed by using SOFA score. More severe disease was defined as SOFA score $\geq \mathrm{a}$ median value of 12 .

\section{Primary outcome}

The primary outcome was overall survival measured from the date of the initiation of CRRT until death or day 30 .

\section{Statistical analyses}

Continuous variables were expressed as mean $\pm \mathrm{SD}$, and compared with $t$-test and one-way ANOVA. To compare between subgroups, post-hoc analysis was performed with Bonferroni analysis. The normality of the distribution of parameters was analysed by using the KolmogorovSmirnov test. If data did not show a normal distribution, these were presented as median and interquartile range and compared by using the Mann-Whitney test or Kruskal-Wallis test. Categorical variables were expressed as percentages and compared with the chi-square test.

To evaluate the relationship of BMI with covariables, and mortality, multivariable-adjusted Cox-proportional hazard models were constructed, and the results were presented as a hazard ratio (HR) and 95\% confidence interval (CI). In model 1, we entered age, sex, CCI score, septic AKI, mean arterial pressure (MAP), eGFR, and SOFA score. We additionally adjusted WBC and albumin as an inflammatory marker and a nutritional marker, respectively, in model 2, and CRRT prescription was further added in model 3 . To evaluate the impact of disease severity on the relationship between BMI and mortality, we first examined interaction between BMI and SOFA score in Cox proportional hazard models. Then, the same analyses were performed according to disease severity status and presence of comorbidities.

In sensitivity analyses, we re-categorized patients by another BMI criteria. The WHO recommends that additional cut-off points of obesity such as $23,27.5,32.5$ and $37.5 \mathrm{~kg} / \mathrm{m}^{2}$ can be used for public health action [24]. Thus, we applied these criteria to confirm our findings. Furthermore, we re-defined disease severity according to APACHE II score. The high disease severity was defined as APACHE II score of $\geq$ a median value of 28 , and Cox regression analyses were repeated after switching SOFA score to APACHE II score. Finally, we performed restricted cubic splines to examine whether the association between disease severity and mortality may differ depending on the presence of obesity. Statistical significance was defined as $P<0.05$. All analyses were conducted by using SPSS, version 23.0 (IBM Corporation, Armonk, NY, USA), SAS version 9.4 (SAS Institute, Cary, NC, USA), and GraphPad Prism version 5.0 (GraphPad Software Inc., San Diego, CA, USA). 


\section{Results}

\section{Patient characteristics}

The baseline characteristics of the patients according to BMI are presented in Table 1 . The mean age was 63.2 years, and 439 patients (38.4\%) were women. The obese group was younger than normal $(P=0.02)$ and overweight group $(P=0.02)$. The average BMI was $23.6(20.9-26.3) \mathrm{kg} / \mathrm{m}^{2}$. The mean CCI score was $3.2 \pm 2.2$ and was similar between groups. Sepsis was a predominant cause of ICU admission and 797 patients $(69.7 \%)$ had undergone sepsis. The most common cause of CRRT was sustained oliguria and did not different between groups. The dose of CRRT was $43.4 \pm$ $16.9 \mathrm{~mL} / \mathrm{kg}$ and obese group received significantly lower CRRT dose than underweight $(P=0.006)$ and normal group $(P<0.001)$. The average SOFA and APACHE II score were $12.1 \pm 3.6$ and $27.1 \pm 8.4$, respectively. The SOFA score was significantly higher in obese group than in underweight $(P$ $=0.02)$ and normal group $(P=0.03)$; however, APACHE II score did not differ between groups $(P=0.44)$. The baseline characteristics according to disease severity are presented in Table 2. BMI was significantly higher in the high severity group than in the low severity group [23.4 (20.8-25.9) vs. $\left.23.9(21.2-26.7) \mathrm{kg} / \mathrm{m}^{2}, P=0.009\right]$. The patients in the low disease severity group had higher prevalence of DM and cardiovascular disease, whereas cancer was more prevalent in the high severity group. As a result, the low severity group had a significantly lower CCI score than the higher severity group $(P=0.002)$. In addition, eGFR and the level of total cholesterol and hemoglobin were lower in the high severity group than in the low severity group. As expected, percentages of patients treated with vasopressor and mechanical ventilation were significantly higher in the high severity group than in the lower severity group $(P<0.001$, respectively).

\section{ICU and hospital stay durations and mortality rates according to BMI classification}

Table 3 shows the ICU and hospital stay durations, survival days, and 30-day mortality rates. The mean ICU and hospital stay was $8(3-17.5)$ and 20 (6-43) days, respectively. Among patients with high severity, the length of hospital stay was longer in the higher BMI groups than in the underweight group, whereas both ICU and hospital stay were longer in the normal BMI group than others, among those with low severity. During 30 days after CRRT initiation, a total of 701 deaths (61.3\%) occurred. The mortality in the obese group was $56.8 \%$, which was significantly lower than in the underweight group $(70.7 \%, P=0.01)$. Among those with high disease severity, obese group had a significantly lower 30th day mortality than the normal $(P<0.001)$ and underweight group $(P=0.007)$. However, this trend was attenuated in patients with low disease severity $(P=0.06)$.

\section{Relationship between BMI and mortality by disease severity in multivariable-adjusted models}

The association between BMI and mortality was further analyzed using multivariable-adjusted Cox models. To this end, we constructed four different models (Table 4). Overall, obesity was significantly associated with a decreased risk of 30-day mortality in the fully adjusted model (HR, 0.81; 95\% CI, 0.68-0.97; $P=0.03$ ). In addition, survival benefit of high BMI was also observed when BMI was treated as a continuous variable (HR, 0.97 per $1 \mathrm{~kg} / \mathrm{m}^{2}$ increase; 95\% CI, 0.96-0.99; $P<0.001)$. Notably, the underweight group was associated with an increased risk of death, but it did not reach statistical significance. As mentioned earlier, the relationship between BMI and mortality is confounded by comorbidity conditions. Therefore, we checked an interaction between BMI and disease severity using Cox regression analysis. When the interaction term was included, we found there was a significant interaction between BMI and SOFA score $(P<0.001)$, suggesting the relationship between BMI and mortality was affected by disease severity. Thus, we further analyzed this association in depth according to disease severity (Table 4 and Fig. 2). Among patients with low severity, the underweight patients were at higher risk of 30-day mortality (HR, 1.74; 95\% CI, 1.16-2.60; $P=$ $0.007)$ than the normal group. In addition, the overweight and the obese groups also had an increased risk of death as compared with the normal group, resulting in U-shaped risk pattern, although it did not reach the statistical significance in the obese group. In contrast, among those with high severity, obesity was significantly associated with a decreased risk of 30-day mortality (HR, 0.61; 95\% CI, 0.48$0.76 ; P<0.001)$ as compared with the normal BMI. However, risk of death did not increase in the underweight and the overweight groups. When BMI was analyzed as a continuous variable, high BMI was independently associated with a decreased risk of death only in the high severity group (HR, 0.96 per $1 \mathrm{~kg} / \mathrm{m}^{2}$ increase; 95\% CI, 0.94-0.98; $P<0.001)$, but not in the low severity group.

\section{Sensitivity analyses}

To confirm our findings, we further analyzed in four groups categorized according to BMI of $<18.50$ (underweight), 18.50-24.99 (normal), 25.00-27.49 (overweight), and $\geq 27.5$ (obesity) $\mathrm{kg} / \mathrm{m}^{2}$. In agreement with the findings in Table 4, the association between BMI and mortality by disease severity remained the same after full adjustment of confounders (Additional file 1: Table S1). Furthermore, when we re-defined higher disease severity as APACHE II score of $\geq 28$, survival benefit of obesity was observed only in the high severity group. (Additional file 2: Table S2). This finding was more evidenced by cubic spline curves. The results showed that disease severity assessed by SOFA score was significantly associated with mortality only in 
Table 1 Baseline characteristics of patients according to BMI classification

\begin{tabular}{|c|c|c|c|c|c|c|}
\hline & \multicolumn{4}{|l|}{ BMl classification } & \multirow[t]{2}{*}{ Total } & \multirow[t]{2}{*}{$p$-value } \\
\hline & Underweight & Normal & Overweight & Obesity & & \\
\hline Number & 99 & 403 & 220 & 422 & 1144 & \\
\hline BMI $\left(\mathrm{kg} / \mathrm{m}^{2}\right)^{\mathrm{a}}$ & $16.9(15-17.8)$ & $21.1(20.1-22.2)$ & $24.1(13.5-24.5)$ & $27.5(25.9-29.2)$ & $23.6(20.9-26.3)$ & $<0.001$ \\
\hline Age (yr) & $62.3 \pm 17.2$ & $65.0 \pm 13.6$ & $63.9 \pm 14.0$ & $61.3 \pm 14.5$ & $63.2 \pm 14.4$ & 0.002 \\
\hline Sex (Female, \%) & $38(38.4)$ & $162(40.2)$ & 65 (29.5) & $174(41.3)$ & 439 (38.4) & 0.03 \\
\hline $\mathrm{DM}(n, \%)$ & 27 (27.6) & $140(34.7)$ & 79 (35.9) & $153(36.3)$ & 399 (34.9) & 0.42 \\
\hline HTN $(n, \%)$ & $40(40.4)$ & $217(53.8)$ & $110(50.0)$ & $233(55.3)$ & $600(52.5)$ & 0.05 \\
\hline $\mathrm{Ml}(n, \%)$ & $10(10.1)$ & $47(11.7)$ & $17(7.7)$ & $37(8.8)$ & $111(9.7)$ & 0.37 \\
\hline $\mathrm{CHF}(n, \%)$ & $20(20.2)$ & $71(17.6)$ & $37(16.8)$ & $57(13.5)$ & $185(16.2)$ & 0.26 \\
\hline CVA $(n, \%)$ & $7(7.1)$ & $50(12.4)$ & $25(11.4)$ & $35(8.3)$ & $117(10.2)$ & 0.08 \\
\hline $\operatorname{PVD}(n, \%)$ & $6(6.1)$ & $15(3.7)$ & $12(5.5)$ & $13(3.1)$ & $46(4.0)$ & 0.35 \\
\hline $\operatorname{COPD}(n, \%)$ & $11(11.0)$ & $33(8.2)$ & $13(5.9)$ & $23(5.5)$ & $80(7.0)$ & 0.15 \\
\hline \multicolumn{7}{|l|}{ Cancer $(n, \%)$} \\
\hline Solid tumor & $18(18.4)$ & $96(23.8)$ & $51(23.3)$ & $93(22.1)$ & $258(22.6)$ & \\
\hline Metastasis & $5(5.1)$ & $19(4.7)$ & $18(8.2)$ & $26(6.2)$ & $68(6.0)$ & 0.77 \\
\hline Leukemia & $3(3.1)$ & $19(4.7)$ & $13(5.9)$ & $16(3.8)$ & $51(4.5)$ & \\
\hline Lymphoma & $12(12.2)$ & $37(9.2)$ & $21(9.6)$ & $38(9.0)$ & $108(9.5)$ & \\
\hline CCl score & $3.1 \pm 2.4$ & $3.2 \pm 2.2$ & $3.1 \pm 2.2$ & $3.2 \pm 2.3$ & $3.2 \pm 2.2$ & 0.94 \\
\hline Sepsis $(n, \%)$ & $74(74.7)$ & $294(73.0)$ & $149(67.7)$ & $280(66.5)$ & 797 (69.7\%) & 0.13 \\
\hline Postop AKI $(n, \%)$ & $3(3.0)$ & $13(3.2)$ & $9(4.1)$ & $26(6.2)$ & $51(4.5)$ & 0.18 \\
\hline \multicolumn{7}{|l|}{ Cause of CRRT } \\
\hline Volume overload & $8(8.1)$ & $62(15.3)$ & $26(11.8)$ & $64(15.2)$ & $160(13.9)$ & \\
\hline Metabolic acidosis & $26(26.3)$ & $85(21.1)$ & $43(19.5)$ & $88(20.8)$ & $242(21.2)$ & \\
\hline Hyperkalemia & $2(2.0)$ & $19(4.7)$ & $12(5.4)$ & $25(5.9)$ & $58(5.1)$ & 0.86 \\
\hline Uremia & $13(13.1)$ & $35(8.7)$ & $21(9.5)$ & $46(10.9)$ & $115(10.1)$ & \\
\hline Oliguria & $35(35.4)$ & $112(27.5)$ & $54(24.5)$ & $93(22.0)$ & $294(25.7)$ & \\
\hline Others & $15(15.2)$ & $90(22.4)$ & $64(29.1)$ & $106(25.1)$ & $275(24.0)$ & \\
\hline CRRT dose (mL/kg) & $46.2 \pm 16.4$ & $44.6 \pm 19.4$ & $41.3 \pm 15.1$ & $40.0 \pm 15.0$ & $43.4 \pm 16.9$ & $<0.001$ \\
\hline MAP $(\mathrm{mmHg})$ & $76.6 \pm 17.5$ & $77.4 \pm 14.2$ & $77.3 \pm 14.3$ & $77.7 \pm 14.5$ & $77.5 \pm 14.6$ & 0.92 \\
\hline Creatinine $(\mathrm{mg} / \mathrm{dL})$ & $2.6 \pm 1.5$ & $2.5 \pm 1.3$ & $2.9 \pm 1.9$ & $2.9 \pm 1.7$ & $2.7 \pm 1.6$ & 0.001 \\
\hline $\operatorname{eGFR}\left(\mathrm{mL} / \mathrm{min} / 1.73 \mathrm{~m}^{2}\right)$ & $33.2 \pm 18.0$ & $33.1 \pm 22.3$ & $32.7 \pm 24.4$ & $29.0 \pm 18.8$ & $31.5 \pm 21.4$ & 0.03 \\
\hline Albumin (g/dL) & $2.5 \pm 0.5$ & $2.6 \pm 0.6$ & $2.6 \pm 0.6$ & $2.6 \pm 0.6$ & $2.6 \pm 0.6$ & 0.47 \\
\hline Total cholesterol (mg/dL) & $111.9 \pm 55.9$ & $107.6 \pm 48.5$ & $98.1 \pm 46.5$ & $108.1 \pm 68.9$ & $106.2 \pm 57.3$ & 0.56 \\
\hline WBC $\left(\times 10^{3} / \mathrm{mm}^{3}\right)$ & $15.3 \pm 25.9$ & $13.8 \pm 11.7$ & $14.7 \pm 12.8$ & $13.7 \pm 9.9$ & $14.1 \pm 13.2$ & 0.64 \\
\hline Hemoglobin (g/dL) & $9.7 \pm 2.4$ & $9.7 \pm 2.1$ & $9.4 \pm 2.4$ & $9.6 \pm 2.3$ & $9.6 \pm 2.3$ & 0.56 \\
\hline $\mathrm{CRP}(\mathrm{mg} / \mathrm{L})^{\mathrm{a}}$ & $37.1(10.6-213.8)$ & $87.3(17.7-171.7)$ & $72.9(18.6-255.7)$ & $56.7(14.2-151.8)$ & $67.5(15.4-164.1)$ & 0.06 \\
\hline Vasopressor $(n, \%)$ & $68(68.9)$ & $270(67.0)$ & $165(75.3)$ & $314(74.4)$ & $817(71.4)$ & 0.15 \\
\hline Ventilator $(n, \%)$ & $80(81.0)$ & $345(85.7)$ & $184(83.7)$ & $352(83.5)$ & $961(84.0)$ & 0.74 \\
\hline SOFA & $11.3 \pm 3.4$ & $11.8 \pm 3.7$ & $12.0 \pm 3.5$ & $12.5 \pm 3.5$ & $12.1 \pm 3.6$ & 0.005 \\
\hline APACHE ॥ & $26.4 \pm 8.3$ & $27.4 \pm 8.0$ & $27.5 \pm 9.1$ & $26.7 \pm 8.4$ & $27.1 \pm 8.4$ & 0.44 \\
\hline
\end{tabular}

Abbreviations: DM diabetes mellitus, HTN hypertension, $M I$ myocardiac infarction, $C H F$ congestive heart failure, $C V A$ cerebrovascular attack, $P V D$ peripheral vascular disease, COPD chronic obstructive pulmonary disease, CCI Charlson comorbidity index, AKI acute kidney injury, BMI body mass index, MAP mean arterial pressure, eGFR estimated glomerular filtration rate, WBC white blood cell, SOFA sepsis-related organ failure assessment

${ }^{a}$ Data were expressed as a median and interquartile range and compared by Kruskal-Wallis test 
Table 2 Baseline characteristics of patients according to disease severity groups

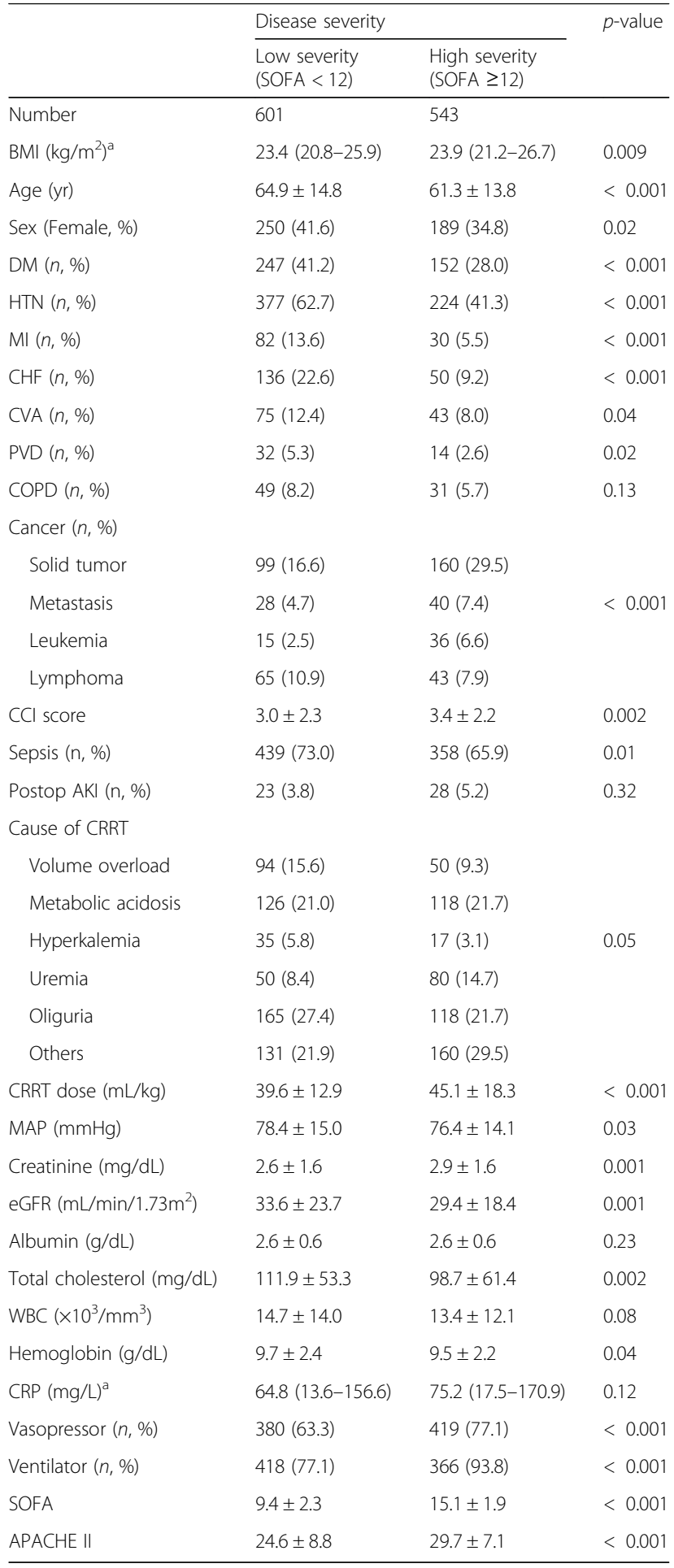

Abbreviations: DM diabetes mellitus, HTN hypertension, $M I$ myocardial infarction, CHF congestive heart failure, CVA cerebrovascular attack, PVD peripheral vascular disease, COPD chronic obstructive pulmonary disease, $C C l$ Charlson comorbidity index, $A K I$ acute kidney injury, $B M I$ body mass index, MAP mean arterial pressure, eGFR estimated glomerular filtration rate, WBC white blood cell, SOFA sepsis-related organ failure assessment ${ }^{a}$ Data were expressed as a median and interquartile range and compared by Mann Whitney $\mathrm{U}$ test non-obese patients, whereas this association was lost in obese patients (Additional file 3: Figure S1).

\section{Subgroup analyses on the relationship between BMI and mortality according to disease severity}

We further analyzed the impact of disease severity on the association between BMI and mortality in several subgroups (Fig. 3), which were stratified by age, sex, diabetes, cardiovascular disease, and cancer. In Cox regression models after full adjustment and BMI as a continuous variable, trends toward a decreased risk of death in high BMI were consistently observed across the subgroups.

\section{Discussion}

In this study, we showed the different relationships between BMI and mortality according to the disease severity in AKI patients undergoing CRRT. Using different multivariable-adjusted models, we found a U-shaped risk pattern of mortality in the low severity group, whereas survival advantage of high BMI was consistently observed in the high severity group. Thus, our findings suggest that disease severity can modify the recently prevailing concept of the "obesity paradox" in critically ill patients undergoing continuous renal replacement therapy.

Previous meta-analyses and observational studies involving a large number of ICU patients have suggested that patients with a higher BMI are more likely to survive than those with a lower BMI $[13,16,17]$. We particularly paid attention to patients with AKI requiring CRRT. Critically ill patients are generally hypercatabolic and have substantial energy expenditure in proportion to high level of stress [25, 26]. In addition, patients with AKI have a high prevalence of malnutrition [27], and protein is excessively degraded by AKI-induced uraemia [28]. Notably, loss of protein is accelerated in AKI patients undergoing CRRT because protein and other nutritional elements are lost through CRRT [29]. It was also found that centrally infused protein losses into CRRT effluent range from 10 to $17 \%$ [30-32]. In this regard, AKI patients on CRRT are more susceptible to a loss of energy reserve. The unique characteristics of these patients can explain why high BMI provided survival advantage in patients with high disease severity.

Conversely, high BMI itself has been considered as a significant risk factor of AKI. A recent observational cohort studies found that obese patients were at a higher risk of developing AKI than patients with normal BMI $[6,7]$. Interestingly, BMI plays a different role in acutely ill patients after having AKI. In a study by Druml et al. [7] involving 5232 patients with 'failure' stage by RIFLE criteria, patients with BMI of $30-35 \mathrm{~kg} / \mathrm{m}^{2}$ had the lowest risk of death compared to those with other BMI categories. This finding was contradicted by Danziger et al. [6]. They found that relative risks of hospital and l-year mortality in obese AKI group were greater than 
Table 3 Length of stay, survival, and mortality according to BMI classification and disease severity

\begin{tabular}{|c|c|c|c|c|c|c|c|}
\hline \multirow[t]{2}{*}{ Disease severity } & \multirow[t]{2}{*}{ Variables } & \multirow[b]{2}{*}{$\begin{array}{l}\text { Underweight } \\
(N=99)\end{array}$} & \multicolumn{3}{|c|}{ BMl classification } & \multirow[t]{2}{*}{ Total } & \multirow[t]{2}{*}{$p$-value } \\
\hline & & & $\begin{array}{l}\text { Normal } \\
(N=403)\end{array}$ & $\begin{array}{l}\text { Overweight } \\
(N=220)\end{array}$ & $\begin{array}{l}\text { Obesity } \\
(N=422)\end{array}$ & & \\
\hline \multirow[t]{3}{*}{ Low } & ICU $\operatorname{LOS}(\mathrm{d})^{\mathrm{a}}$ & $5(2-14)$ & $12(5-26)$ & $6.5(3-14.5)$ & $8(3-15)$ & $8(3-18)$ & 0.001 \\
\hline & Hospital LOS $(d)^{a}$ & $9.5(2.3-44.5)$ & $28(14-63.5)$ & $25.5(10-48)$ & $22(9-42)$ & $23(10-48)$ & 0.002 \\
\hline & Mortality 30th day (n, \%) & $38(61.3)$ & $93(43.5)$ & $66(53.2)$ & $97(48.5)$ & $294(49.0)$ & 0.06 \\
\hline \multirow[t]{3}{*}{ High } & ICU LOS $(d)^{a}$ & $4(1-12)$ & $5(2-14)$ & $5(3-18)$ & $8(3-18)$ & $7(2.5-17)$ & 0.61 \\
\hline & Hospital LOS (d) ${ }^{\mathrm{a}}$ & $5(2-18.5)$ & $10(2-27)$ & $16(3-37)$ & $18.5(6-40.8)$ & $15(4-35)$ & 0.002 \\
\hline & Mortality 30th day (n, \%) & $32(86.5)$ & $163(86.2)$ & $70(72.9)$ & $142(64.3)$ & $407(74.9)$ & $<0.001$ \\
\hline \multirow[t]{3}{*}{ Total } & ICU LOS (d) ${ }^{\mathrm{a}}$ & $5(2-14)$ & $9(3-20)$ & $6(3-15)$ & $8(3-16)$ & $8(3-17.5)$ & 0.03 \\
\hline & Hospital LOS (d) ${ }^{\mathrm{a}}$ & $8(2-30)$ & $20(7-46)$ & $23(6.5-45.5)$ & $21(8-41)$ & $20(6-43)$ & 0.006 \\
\hline & Mortality 30th day (n, \%) & $70(70.7)$ & $256(63.5)$ & $136(61.8)$ & $239(56.8)$ & $701(61.3)$ & 0.04 \\
\hline
\end{tabular}

Abbreviations: ICU intensive care unit, LOS length of stay

${ }^{\mathrm{a}}$ Data are expressed as a median and interquartile range and compared by Kruskal-Wallis test

other BMI groups. This discrepancy can partially be explained by different disease severity between the studies. In fact, in the study by Druml et al., the median value of the Simplified Acute Physiology Score II was 47 and overall ICU and hospital mortality rates were $56.1 \%$ and $63.9 \%$. However, disease severity was much lower in the study by Danziger et al., where overall hospital mortality was only $10 \%$ and baseline serum creatinine was $1.1-1.4 \mathrm{mg} / \mathrm{dL}$ without detailed information of SOFA score. It is possible that there is a biphasic role of obesity depending on disease severity. To corroborate this, we found that high BMI was consistently associated with a decreased risk of death among patients with high severity, but there was a U-shaped pattern for mortality among those with low severity.
It is generally accepted that fat tissue can function as an energy reservoir. In addition, severe illness can worsen high catabolic state, protein loss, and muscle wasting. Thus, when disease is severe, obese patients having high energy store can tolerate stressful and damaging conditions better than non-obese patients [33]. In contrast, energy-storage role of fat do not appear to play a significant role in patients with low disease severity. Presumably, energy-consuming process and muscle wasting are diminished when disease burden is less severe. The relatively well-preserved nutritional status in patients with low disease severity can also support the findings of favourable effect between obesity and mortality in this group. A recent study by Robinson et al. investigated the relationship among obesity, nutritional status, and mortality [19]. They showed that high

Table 4 Multivariable Cox regression analyses for 30-day mortality

\begin{tabular}{|c|c|c|c|c|c|c|c|c|c|}
\hline \multirow{2}{*}{$\begin{array}{l}\text { Disease } \\
\text { severity }\end{array}$} & \multirow{2}{*}{$\begin{array}{l}\text { BMI } \\
\text { classification }\end{array}$} & \multicolumn{2}{|l|}{ Model 1} & \multicolumn{2}{|l|}{ Model 2} & \multicolumn{2}{|l|}{ Model 3} & \multicolumn{2}{|l|}{ Model 4} \\
\hline & & HR $(95 \% \mathrm{Cl})$ & $p$-value & HR (95\% Cl) & $p$-value & HR $(95 \%$ Cl) & $p$-value & HR $(95 \% \mathrm{Cl})$ & $p$-value \\
\hline \multirow[t]{4}{*}{ Low } & Underweight & $1.57(1.07-2.30)$ & 0.02 & $1.66(1.13-2.45)$ & 0.01 & $1.74(1.16-2.60)$ & 0.007 & $0.99(0.96-1.01)$ & 0.36 \\
\hline & Normal & 1.00 (Reference) & & 1.00 (Reference) & & 1.00 (Reference) & & & \\
\hline & Overweight & $1.44(1.05-1.99)$ & 0.03 & $1.48(1.07-2.04)$ & 0.02 & $1.41(1.02-1.94)$ & 0.04 & & \\
\hline & Obesity & $1.31(0.98-1.76)$ & 0.07 & $1.35(1.01-1.82)$ & 0.04 & $1.28(0.95-1.72)$ & 0.11 & & \\
\hline \multirow[t]{4}{*}{ High } & Underweight & $1.07(0.73-1.56)$ & 0.74 & $1.03(0.70-1.51)$ & 0.9 & $1.04(0.70-1.53)$ & 0.86 & $0.96(0.94-0.98)$ & $<0.001$ \\
\hline & Normal & 1.00 (Reference) & & 1.00 (Reference) & & 1.00 (Reference) & & & \\
\hline & Overweight & $0.79(0.60-1.05)$ & 0.11 & $0.81(0.61-1.07)$ & 0.14 & $0.78(0.58-1.03)$ & 0.08 & & \\
\hline & Obesity & $0.63(0.50-0.79)$ & $<0.001$ & $0.64(0.51-0.80)$ & $<0.001$ & $0.61(0.48-0.76)$ & $<0.001$ & & \\
\hline \multirow[t]{4}{*}{ Total } & Underweight & $1.27(0.97-1.66)$ & 0.08 & $1.27(0.97-1.67)$ & 0.08 & $1.28(0.97-1.68)$ & 0.08 & $0.97(0.96-0.99)$ & $<0.001$ \\
\hline & Normal & 1.00 (Reference) & & 1.00 (Reference) & & 1.00 (Reference) & & & \\
\hline & Overweight & $1.02(0.83-1.26)$ & 0.87 & $1.02(0.83-1.27)$ & 0.83 & $0.99(0.80-1.22)$ & 0.89 & & \\
\hline & Obesity & $0.84(0.70-1.01)$ & 0.06 & $0.86(0.72-1.03)$ & 0.1 & $0.81(0.68-0.97)$ & 0.03 & & \\
\hline
\end{tabular}

Model 1: age, sex, $\mathrm{CCl}$ score, septic AKI, MAP, eGFR, and SOFA score

Model 2: Model $1+$ WBC and albumin

Model 3: Model $2+$ CRRT prescription (total effluent volume)

Model 4: Model $3+\mathrm{BMI}$ as a continuous variable 
a

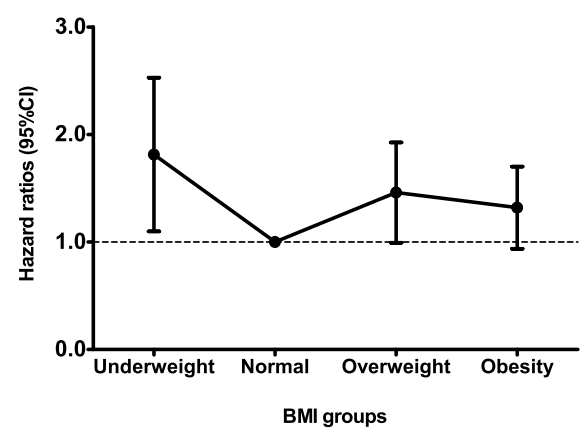

b

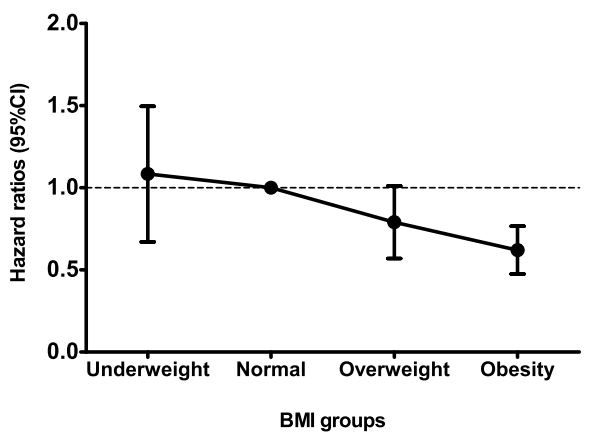

Fig. 2 The relationship between BMl groups and 30-day mortality in fully adjusted Cox regression model. a low severity, b high severity

BMI was significantly associated with survival benefit in critical ill patients. Of note, in their findings, malnutrition was less prevalent in obese patients than in underweight and normal patients, suggesting nutrition as a potential factor to explain survival advantage of obesity. Thus, when nutritional status is poor accompanied by high disease severity, energy-storing fat can compensate for the loss of energy and decline in nutritional status. Conversely, better nutritional status in low disease severity can attenuate the favourable effects of high BMI. In this regard, future studies should address the association between BMI, disease severity, and nutritional status in critically ill patients with AKI.

There are several limitations that should be discussed in this study. First, to clarify the association between BMI and mortality, we constructed various multivariable models adjusted for many potential factors. However, this is an observational study and unknown bias may affect the study results and our findings need to be interpreted with caution. Second, only BMI was applied to define obesity. BMI provides an easy way to measure obesity and has been widely used. However, BMI has been criticized because it is not an accurate measure of fat [34]. Other parameters such as waist circumference or abdominal diameter can be added to increase the diagnostic accuracy for obesity [35]. Unfortunately, such measurement was not easily feasible in the ICU setting, particularly when patients are in critical condition. Third, we used the BMI classification proposed by the Committee of Clinical Practice Guidelines and Korean Society for the Study of Obesity [23]. When the WHO international criteria were applied, only $6.9 \%$ of patients had BMI $>30 \mathrm{~kg} / \mathrm{m}^{2}$ in our study. Thus, analysis for morbid obese patients was not feasible and result of our study may not be applicable to other ethnic groups, whose BMI is higher than our population. We confirmed our findings using a different flexible BMI classification for the Asian population proposed by the WHO [24] as indicated in Additional file 1: Table S1. Although we defined obesity as $\mathrm{BMI} \geq 27.5 \mathrm{~kg} / \mathrm{m}^{2}$, the results were unaltered. Nevertheless, we acknowledge well that BMI

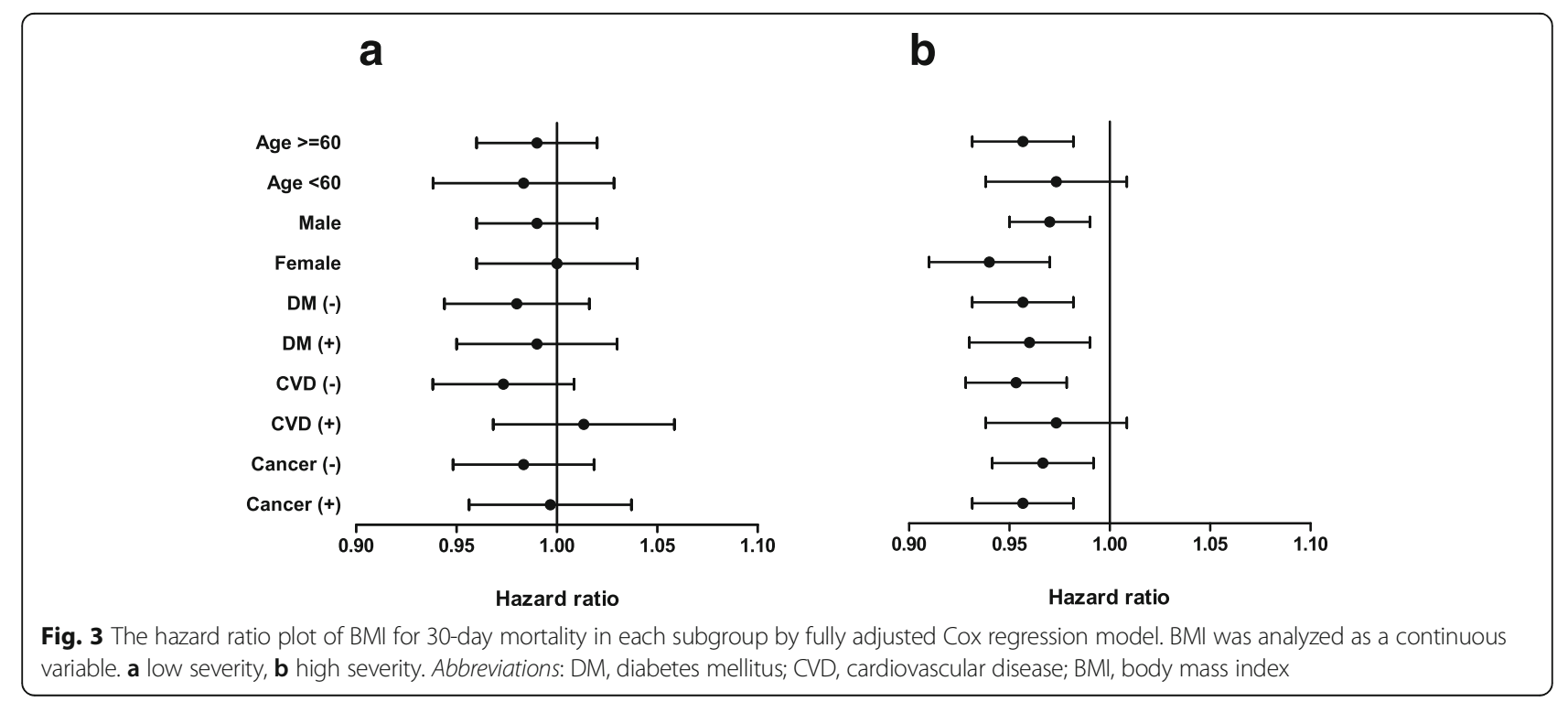


cut-off point for obesity in this study is lower than that in other Western countries and thus our findings may not be extrapolated to such extremely obese patients. Further studies with large number of obese patients should focus on this issue. Fourth, our database did not have much information on nutritional indices, thus nutritional status could not be thoroughly evaluated. However, all nutritional supports including whether or not to start enteral or parenteral nutrition were precisely decided by dietitians and intensivists upon ICU admission in our centers. Finally, CRRT prescription was different across BMI and disease severity groups. Patients with high BMI tended to have less amount of dialysis, and this tendency was persistent in both disease severity groups (data not shown). We showed better survival of high BMI patients even with low dose of dialysis; however, it is uncertain whether CRRT dose can affect to mortality in AKI patients undergoing CRRT [36].

\section{Conclusions}

In conclusion, this study showed that high BMI is associated with survival benefit in AKI patients undergoing CRRT. However, this association was observed only in patients with high disease severity. Our findings suggest that disease severity can modify an inverse relationship between high BMI and mortality in these patients. Thus, interpretation of this relationship should be made with caution depending on disease severity. Further studies are required to evaluate whether BMI can be incorporated into risk stratification depending on disease severity in critically ill patients.

\section{Additional files}

Additional file 1: Table S1. Multivariate Cox regression analyses for 30-day mortality by WHO classification. (DOCX $18 \mathrm{~kb}$ )

Additional file 2: Table S2. Multivariate Cox regression analyses for 30-day mortality by APACHE II score. (DOCX $18 \mathrm{~kb}$ )

Additional file 3: Figure S1. The cubic spline curves for 30-day mortality according to SOFA score. (a) non-obese group, (b) obese group. Abbreviations: SOFA, sepsis-related organ failure assessment. (PDF $737 \mathrm{~kb}$ )

\section{Abbreviations}

AKI: Acute kidney injury; APACHE: Acute Physiology and Chronic Health Evaluation; BMI: Body mass index; CCl: Charlson comorbidity index score; $\mathrm{Cl}$ : Confidence interval; CKD: Chronic kidney disease; CRP: C-reactive protein; CRRT: Continuous renal replacement therapy; DM: Diabetes mellitus; eGFR: estimated glomerular filtration rate; ESRD: End-stage renal disease; HR: Hazard ratio; ICU: Intensive care unit; IRB: Institutional review board; SOFA: Sepsis-related organ failure assessment; WBC: White blood cell; WHO: World Health Organization

\section{Acknowledgements}

None

\section{Funding}

Not applicable

\section{Availability of data and materials}

The data that support the findings of this study are available from the corresponding author upon reasonable request.

\section{Authors' contributions}

Study conception and design was collaboratively conducted by HJO, JTP, TIC, THY, SWK, and SHH. Data were collected by HK, HK, ML, MUC, KHN, SYA, SYJ, JHJ, SP, HRY, and YKK. Interpretation of data and statistical analyses were performed by HK, HK, ML, MUC, KHN, SYA, SYJ, JHJ, SP, HRY, and YKK.

Manuscript was written by HK, HK, HJO, JTP, TIC, THY, SWK and SHH. HK and $\mathrm{SHH}$ critically revised the manuscript for important intellectual content. All authors read and approved final manuscript.

\section{Ethics approval and consent to participate}

The study was performed in accordance with the Declaration of Helsinki and approved by the institutional review board (IRB) of the Yonsei University Health System (YUHS) Clinical Trial Center and National Health Insurance Service Medical Center, Ilsan Hospital. Although all patients in this study were informed about the description of investigations, this was conducted as a medical record-based retrospective analysis and the included subjects were anonymized. Therefore, the IRB approved the exemption from obtaining written consent.

\section{Consent for publication}

Not applicable

\section{Competing interests}

The authors declare that they have no competing interests

\section{Publisher's Note}

Springer Nature remains neutral with regard to jurisdictional claims in published maps and institutional affiliations.

\section{Author details}

'Department of Internal Medicine, Institute of Kidney Disease Research, Yonsei University College of Medicine, 50-1 Yonsei-ro, Seodaemun-Gu, Seoul 03722, South Korea. 'Division of Nephrology, Soonchunhyang University, Seoul, Republic of Korea. ${ }^{3}$ Ewha Institute of Convergence Medicine, Ewha Womans University Mokdong Hospital, Seoul, Republic of Korea. ${ }^{4}$ Division of Nephrology, Department of Internal Medicine, National Health Insurance Service Medical Center, Ilsan Hospital, Goyang, Gyeonggi-do, Republic of Korea.

Received: 6 August 2017 Accepted: 24 January 2018

Published online: 07 February 2018

\section{References}

1. Alberti KG, Eckel RH, Grundy SM, Zimmet PZ, Cleeman Jl, Donato KA, et al. Harmonizing the metabolic syndrome: a joint interim statement of the international diabetes federation task force on epidemiology and prevention: National Heart, Lung, and Blood Institute; American Heart Association; world heart federation; international atherosclerosis society; and International Association for the Study of obesity. Circulation. 2009;120(16):1640-5.

2. Thomas G, Sehgal AR, Kashyap SR, Srinivas TR, Kirwan JP, Navaneethan SD. Metabolic syndrome and kidney disease: a systematic review and metaanalysis. Clin J Am Soc Nephrol. 2011;6(10):2364-73.

3. Akinnusi ME, Pineda LA, El Solh AA. Effect of obesity on intensive care morbidity and mortality: a meta-analysis. Crit Care Med. 2008;36(1):151-8.

4. Chertow GM, Burdick E, Honour M, Bonventre JV, Bates DW. Acute kidney injury, mortality, length of stay, and costs in hospitalized patients. J Am Soc Nephrol. 2005;16(11):3365-70.

5. Soto GJ, Frank AJ, Christiani DC, Gong MN. Body mass index and acute kidney injury in the acute respiratory distress syndrome. Crit Care Med. 2012;40(9):2601-8

6. Danziger J, Chen KP, Lee J, Feng M, Mark RG, Celi LA, et al. Obesity, acute kidney injury, and mortality in critical illness. Crit Care Med. 2016;44(2):328-34.

7. Druml W, Metnitz B, Schaden E, Bauer P, Metnitz PG. Impact of body mass on incidence and prognosis of acute kidney injury requiring renal replacement therapy. Intensive Care Med. 2010;36(7):1221-8.

8. Plataki M, Kashani K, Cabello-Garza J, Maldonado F, Kashyap R, Kor DJ, et al. Predictors of acute kidney injury in septic shock patients: an observational cohort study. Clin J Am Soc Nephrol. 2011;6(7):1744-51. 
9. El-Solh A, Sikka P, Bozkanat E, Jaafar W, Davies J. Morbid obesity in the medical ICU. Chest. 2001;120(6):1989-97.

10. Bercault N, Boulain T, Kuteifan K, Wolf M, Runge I, Fleury JC. Obesity-related excess mortality rate in an adult intensive care unit: a risk-adjusted matched cohort study. Crit Care Med. 2004;32(4):998-1003.

11. Ray DE, Matchett SC, Baker K, Wasser T, Young MJ. The effect of body mass index on patient outcomes in a medical ICU. Chest. 2005;127(6):2125-31.

12. Tremblay A, Bandi V. Impact of body mass index on outcomes following critical care. Chest. 2003;123(4):1202-7.

13. Oliveros $\mathrm{H}$, Villamor E. Obesity and mortality in critically ill adults: a systematic review and meta-analysis. Obesity (Silver Spring). 2008;16(3):515-21.

14. Chao CT, Wu VC, Tsai HB, Wu CH, Lin YF, Wu KD, et al. Impact of body mass on outcomes of geriatric postoperative acute kidney injury patients. Shock. 2014;41(5):400-5.

15. Arabi YM, Dara SI, Tamim HM, Rishu AH, Bouchama A, Khedr MK, et al. Clinical characteristics, sepsis interventions and outcomes in the obese patients with septic shock: an international multicenter cohort study. Crit Care. 2013;17(2):R72.

16. Pickkers P, de Keizer N, Dusseljee J, Weerheijm D, van der Hoeven JG, Peek N. Body mass index is associated with hospital mortality in critically ill patients: an observational cohort study. Crit Care Med. 2013;41(8):1878-83.

17. Hogue CW Jr, Stearns JD, Colantuoni E, Robinson KA, Stierer T, Mitter N, et al. The impact of obesity on outcomes after critical illness: a meta-analysis. Intensive Care Med. 2009;35(7):1152-70.

18. De Schutter A, Kachur S, Lavie CJ, Boddepalli RS, Patel DA, Milani RV. The impact of inflammation on the obesity paradox in coronary heart disease. Int J Obes. 2016;40(11):1730-5.

19. Robinson MK, Mogensen KM, Casey JD, CK MK, Moromizato T, Rawn JD, et al. The relationship among obesity, nutritional status, and mortality in the critically ill. Crit Care Med. 2015:43(1):87-100.

20. Charlson ME, Pompei P, Ales KL, CR MK. A new method of classifying prognostic comorbidity in longitudinal studies: development and validation. J Chronic Dis. 1987;40(5):373-83.

21. Levey AS, Bosch JP, Lewis JB, Greene T, Rogers N, Roth D. A more accurate method to estimate glomerular filtration rate from serum creatinine: a new prediction equation. Modification of diet in renal disease study group. Ann Intern Med. 1999;130(6):461-70.

22. Jih J, Mukherjea A, Vittinghoff E, Nguyen TT, Tsoh JY, Fukuoka Y, et al. Using appropriate body mass index cut points for overweight and obesity among Asian Americans. Prev Med. 2014;65:1-6.

23. Kim MK, Lee WY, Kang JH, Kang JH, Kim BT, Kim SM, et al. 2014 clinica practice guidelines for overweight and obesity in Korea. Endocrinol Metab (Seoul). 2014;29(4):405-9.

24. WHO Expert Consultation. Appropriate body-mass index for Asian populations and its implications for policy and intervention strategies. Lancet. 2004;363(9403):157-63.

25. Hwang TL, Huang SL, Chen MF. The use of indirect calorimetry in critically ill patients-the relationship of measured energy expenditure to injury severity score, septic severity score, and APACHE II score. J Trauma. 1993;34(2):247-51.

26. Uehara M, Plank LD, Hill GL. Components of energy expenditure in patients with severe sepsis and major trauma: a basis for clinical care. Crit Care Med. 1999;27(7):1295-302

27. Fiaccadori E, Lombardi M, Leonardi S, Rotelli CF, Tortorella G, Borghetti A. Prevalence and clinical outcome associated with preexisting malnutrition in acute renal failure: a prospective cohort study. J Am Soc Nephrol. 1999;10(3):581-93.

28. Fouque D, Kalantar-Zadeh K, Kopple J, Cano N, Chauveau P, Cuppari L, et al. A proposed nomenclature and diagnostic criteria for protein-energy wasting in acute and chronic kidney disease. Kidney Int. 2008;73(4):391-8.

29. Druml W. Metabolic aspects of continuous renal replacement therapies. Kidney Int Suppl. 1999;56(72):S56-61.

30. Scheinkestel CD, Adams F, Mahony L, Bailey M, Davies AR, Nyulasi I, et al. Impact of increasing parenteral protein loads on amino acid levels and balance in critically ill anuric patients on continuous renal replacement therapy. Nutrition. 2003;19(9):733-40.

31. Bellomo R, Tan HK, Bhonagiri S, Gopal I, Seacombe J, Daskalakis M, et al. High protein intake during continuous hemodiafiltration: impact on amino acids and nitrogen balance. Int J Artif Organs. 2002;25(4):261-8.

32. Scheinkestel CD, Kar L, Marshall K, Bailey M, Davies A, Nyulasi I, et al. Prospective randomized trial to assess caloric and protein needs of critically ill, anuric, ventilated patients requiring continuous renal replacement therapy. Nutrition. 2003;19(11-12):909-16.
33. Kee AL, Isenring E, Hickman I, Vivanti A. Resting energy expenditure of morbidly obese patients using indirect calorimetry: a systematic review. Obes Rev. 2012;13(9):753-65.

34. Romero-Corral A, Somers VK, Sierra-Johnson J, Thomas RJ, Collazo-Clavell $\mathrm{ML}$, Korinek J, et al. Accuracy of body mass index in diagnosing obesity in the adult general population. Int J Obes. 2008;32(6):959-66.

35. Pischon T, Boeing H, Hoffmann K, Bergmann M, Schulze MB, Overvad K, et al. General and abdominal adiposity and risk of death in Europe. N Engl J Med. 2008:359(20):2105-20.

36. Bellomo R, Cass A, Cole L, Finfer S, Gallagher M, Lo S, et al. Intensity of continuous renal-replacement therapy in critically ill patients. N Engl J Med. 2009;361(17):1627-38.

\section{Submit your next manuscript to BioMed Central and we will help you at every step:}

- We accept pre-submission inquiries

- Our selector tool helps you to find the most relevant journal

- We provide round the clock customer support

- Convenient online submission

- Thorough peer review

- Inclusion in PubMed and all major indexing services

- Maximum visibility for your research

Submit your manuscript at www.biomedcentral.com/submit

) BioMed Central 